\title{
South Carolina's Climate Report Card: Understanding South Carolina's Climate Trends and Variability
}

\author{
Hope Mizzell, Mark Malsick and Ivetta Abramyan
}

\begin{abstract}
AUTHORS: S.C. State Climatology Office, S.C. Department of Natural Resources, Columbia, South Carolina, 29209, USA
REFERENCE: Proceedings of the 2012 South Carolina Water Resources Conference, held October 10-11, 2012 at the

Columbia Metropolitan Convention Center.
\end{abstract}

\begin{abstract}
This study provides an overview of South Carolina's climatic trends and variability over the last century. Most studies nationally have focused on large-scale temperature and precipitation trends, but examination of regional and local trends are needed to monitor the significance of the state's climate signal and advance our understanding of the complex physical controls on the region's climate. The behavior of several climatic elements since the 1900s were evaluated for 66 sites in South Carolina and bordering states to determine the variability of the system on annual, seasonal and decadal scales, including the use of threshold approaches to assess climate patterns. Results from the bordering states were not directly discussed, but were included in the study for continuity.

The linear regression model found opposite seasonal trends between minimum temperature and maximum temperature for some stations. The linear trend analysis was more clearly defined for precipitation than for temperature. Most stations experienced a general decreasing trend in summer precipitation totals and an increasing trend in fall precipitation. The 10-year moving averages were able to detect patterns of change over time. The precipitation variables show a decreasing precipitation trend during the $1950 \mathrm{~s}$, increasing trend during the 1960s with a decreasing trend over the past decade. The 10-year moving averages for temperature detect a decreasing temperature trend from the late 1950 s through the 1960 s with a steady temperature increase since the 1970s.

Data on South Carolina tornado occurrences and hurricane landfalls were examined to discern any trends in severe storms. While there does not seem to be an increasing trend in the frequency of tornado occurrences and hurricane landfalls in South Carolina, there is also no evidence that the events are becoming less frequent or less severe.
\end{abstract}

\section{INTRODUCTION}

Climate change has occurred throughout history over timescales that vary from decades to hundreds of thousands of years. Growing questions and concerns over climate change, climate variability and climate extremes have increased the need for research and monitoring activities to better understand the nature of climate fluctuations in South Carolina. The purpose of this study is to examine and document the local climate variability in order to monitor the State's climate signal and better understand the complex controls on the region's climate. Results from the study can help foster better predictions and informed responses to climate variations and extreme events, both on short- and longterm time scales.

\section{PROJECT OBJECTIVES}

The objectives for this study are:

1.) Assemble a temporally complete database of climate observations for stations having reliable and lengthy records spatially distributed across South Carolina. Develop a time series for monthly, seasonal, and annual temperature, precipitation and threshold exceedance data for each location.

2.) Assemble a temporally complete database of tornado events and hurricane landfalls in South Carolina. Develop a time series for event occurrence.

3.) Complete linear trend evaluations and 10-year moving averages for each time series. 


\section{PROJECT DESCRIPTION}

Evaluations of historical precipitation and temperature across the U.S. Southeast reveal much interannual and interdecadal variability (Ingram et al., 2013). Global studies suggest that the U.S. Southeast is one of the few regions that did not experience an overall warming trend in surface temperature during the 20th century (IPCC, 2007). There is also research that suggests that the frequency of extreme temperatures events both warm and cold have declined across much of the Southeast, but with a wide range of decadal and intraregional variability (Kunkel et al., 2013).

The Southeast experiences a wide range of extreme weather and climate events that have resulted in billion-dollar weather disasters over the last three decades (NCDC, 2011). Records of severe events are not as extensive as records of general precipitation and temperature patterns. The best available data on severe thunderstorms, high winds, hail, flooding and tornadoes generally only go back to 1950 . Documentation of these occurrences is also highly sensitive to population density limiting the data to recorded events, not necessarily capturing all events.

While there is more extensive data on hurricanes, there are differing perspectives on the trends of Atlantic Basin hurricane and tropical cyclone frequency (Holland et al., 2007; Landsea, 2007; Landsea et al., 2010). Some scholars contend that the record of tropical activity is likely missing storms during the years before satellite detection (prior to late 1960s) and airplane reconnaissance (prior to mid-1940s). Many studies such as this analysis focus on landfalling storms since they would have likely been verified without satellite or reconnaissance coverage.

While some of the research highlighted above includes South Carolina data, the work is broader in scope and not focused on documenting and detecting localized changes. The purpose of this study is to examine South Carolina's climate variability over the last century by examining seasonal and annual precipitation and temperature records, variations in extreme precipitation and temperature events and the frequency of tornado occurrence and hurricane landfalls. The examination of these trends is needed to monitor the significance of the state's climate signal and advance our understanding of the complex physical controls on the region's climate.

\section{METHODOLOGY}

Changes in South Carolina's surface temperature and precipitation over the last 100 years were analyzed using station data from the National Oceanic and
Atmospheric Administration U.S. Historical Climate Network (USHCN) and the National Weather Service Cooperative Network (COOP). The USHCN is a dataset that includes adjustments for changes in station location, urbanization and time of observation and the COOP network provided the daily data needed for supplemental threshold approach evaluations. Observations from 66 USHCN stations spanning the period 1901-2010 and 26 COOP stations spanning 60 to 100 years provide adequate spatial coverage for the study area.

Since changing climate extremes may have different and potentially greater impacts than changes in the mean, analyzing climate extremes becomes very important. Monitoring and detection of changes in precipitation and temperature extremes requires daily resolution data which were obtained and analyzed from the COOP network for the period 1938-2010. A threshold exceedance analysis for extreme events was conducted for stations around the State. Several extreme thresholds were examined including, the annual number of days with temperature above $95^{\circ}$ $\mathrm{F}$, the Fall-Spring number of days with temperature less than $32^{\circ} \mathrm{F}$, and the annual number of days with precipitation greater than 2.00 ".

Changes in the frequency of tornado occurrence and hurricane landfalls in South Carolina were also examined. Tornado data is only available starting in 1950 and was retrieved from the NOAA Storm Prediction Center Severe Weather database. There is more extensive data on hurricane landfalls in South Carolina which was retrieved and verified by multiple sources including NOAA's Atlantic Hurricane Reanalysis Project. Tornadoes and hurricane landfalls provide an objective measure to evaluate trends and variability in event extremes.

\section{RESULTS}

Seasonal temperature and precipitation trends based on USHCN data were analyzed using the least squares method. Results showed a general precipitation decrease in the majority of the region for summer rainfall totals $(\geq 1.0$ " decrease for 55 out of the 66 stations), with 36 out of the 66 stations experiencing a decreasing precipitation trend $\geq 2.50$ ". The trend analysis for fall rainfall totals was the inverse of summer with all stations across the study area experiencing an increasing precipitation trend (61 stations had an increasing fall precipitation trend $\geq 1.0$ ") (Figure 1). The trends for winter precipitation totals show mixed results with a drier trend in the higher elevations and 

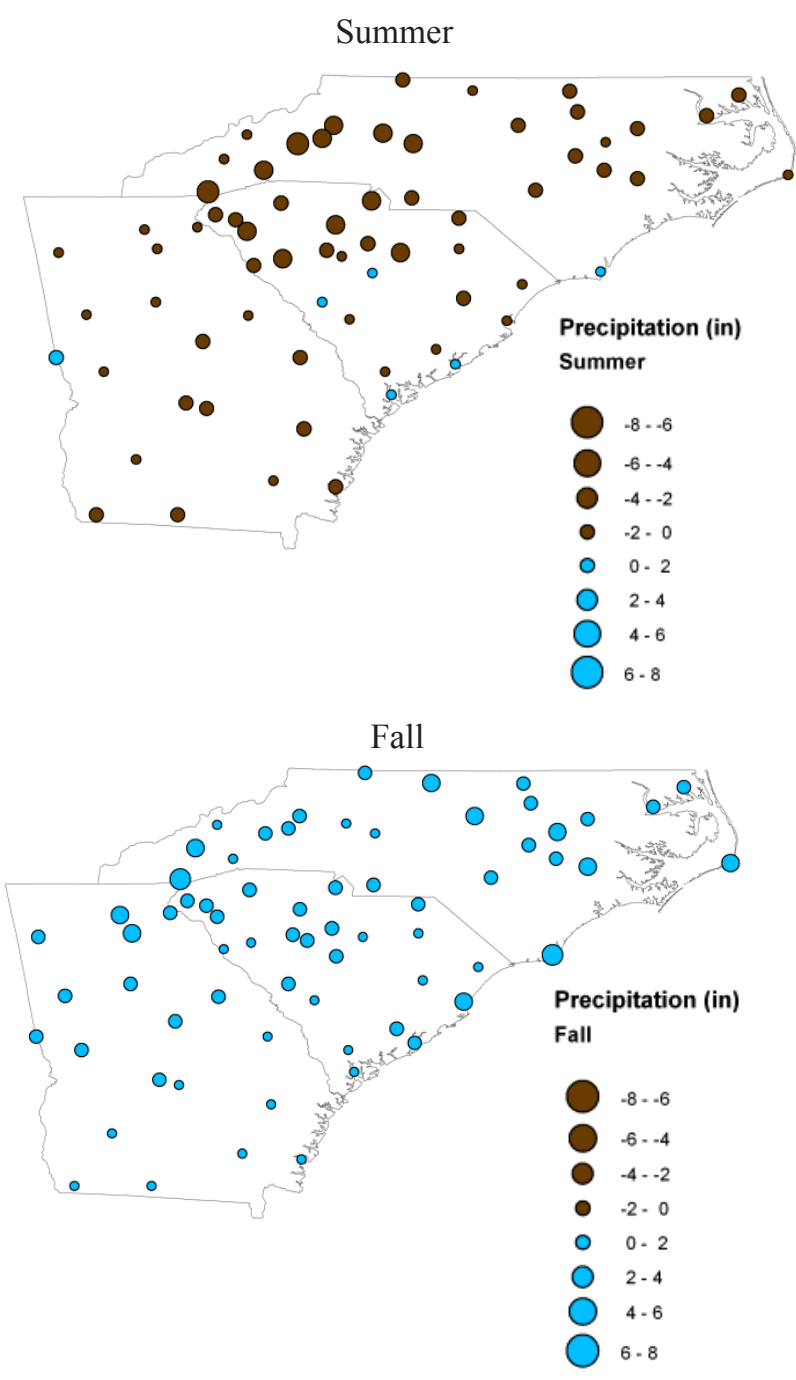

Figure 1. Trends in summer and fall precipitation totals (inches), 1901-2010.

the river headwater regions and a wetter trend from the midlands to the coast. Spring precipitation trends are geographically similar to winter, but with a weakersignal.

Table 1 displays the seasonal and annual precipitation trend for each station. Aiken was the only station with an increasing precipitation trend greater than 1" for all seasons. Seven stations had a decreasing annual precipitation trend greater than 3" while six stations had an increasing annual precipitation trend greater than 3".

South Carolina temperature patterns are less clearly defined with differential changes in minimum temperature (Tmin) and maximum temperature (Tmax). Winter and spring Tmax generally warmed (Figure 2), but the Tmin during these seasons showed little variation or actually cooled over time. Summer and fall Tmax and Tmin don't consistently demonstrate a uniform trend with some stations warming while others cooled across the region.
Table 1. Seasonal and annual USHCN precipitation trends computed from least squares regression, 1901-2010.

\begin{tabular}{|l|r|r|r|r|r|} 
Station & \multicolumn{1}{|l}{ Spring } & Summer & Fall & Winter & Annual \\
\hline Walhalla & -0.3 & -2.8 & 3.4 & -2.4 & -2.2 \\
\hline Clem Univ & -0.7 & -3.3 & 2.3 & -2.9 & -4.8 \\
\hline Anderson & -0.7 & -4.8 & 3.9 & -1.4 & -3.1 \\
\hline Calhoun Falls & -1.3 & -2.5 & 1.9 & -1.5 & -3.3 \\
\hline Greenwood & -0.5 & -5.8 & 1.4 & -2.8 & -7.7 \\
\hline Grvl/Spbg & 0.1 & -2.6 & 2.3 & -2.2 & -2.6 \\
\hline Aiken & 2.8 & 1.9 & 2.8 & 1.7 & 9.2 \\
\hline Blackville & 0.1 & -1.2 & 0.6 & 1 & 0.7 \\
\hline Newberry & -0.3 & -2.8 & 3.8 & -1.6 & -1 \\
\hline Lil Mtn & 0.2 & -1.6 & 2.9 & 0.4 & 1.9 \\
\hline Columbia & 1.4 & 0.6 & 3 & 2.1 & 7.2 \\
\hline Santuck & -0.6 & -4.7 & 2.5 & -1.8 & -4.8 \\
\hline Winnsboro & -0.6 & -3.9 & 2.4 & 0 & -2.1 \\
\hline Camden & -1.3 & -4.1 & 1.4 & -1.3 & -5.3 \\
\hline Winthrop & -0.9 & -4.6 & 3.1 & -1.6 & -4.1 \\
\hline Cheraw & -0.8 & -3 & 2.3 & -0.4 & -1.9 \\
\hline Darlington & -0.2 & -0.4 & 1.5 & 1.4 & 2.3 \\
\hline Kingstree & 1.7 & -3.9 & 1.8 & 1.5 & 1.2 \\
\hline Conway & -0.1 & -1.3 & 1.9 & -0.3 & 0.3 \\
\hline Georgetown & 0.2 & -1.7 & 4.5 & 0.2 & 3.2 \\
\hline Charleston & 0.8 & 0.9 & 3.5 & 0.5 & 5.8 \\
\hline Summerville & 1 & -1 & 3.3 & 0.5 & 4 \\
\hline Beaufort & 0.9 & 0.8 & 3.2 & 0.1 & 3.2 \\
\hline Yemassee & 0.4 & -1.9 & 1.4 & 1.6 & 1.6 \\
\hline & & & & &
\end{tabular}
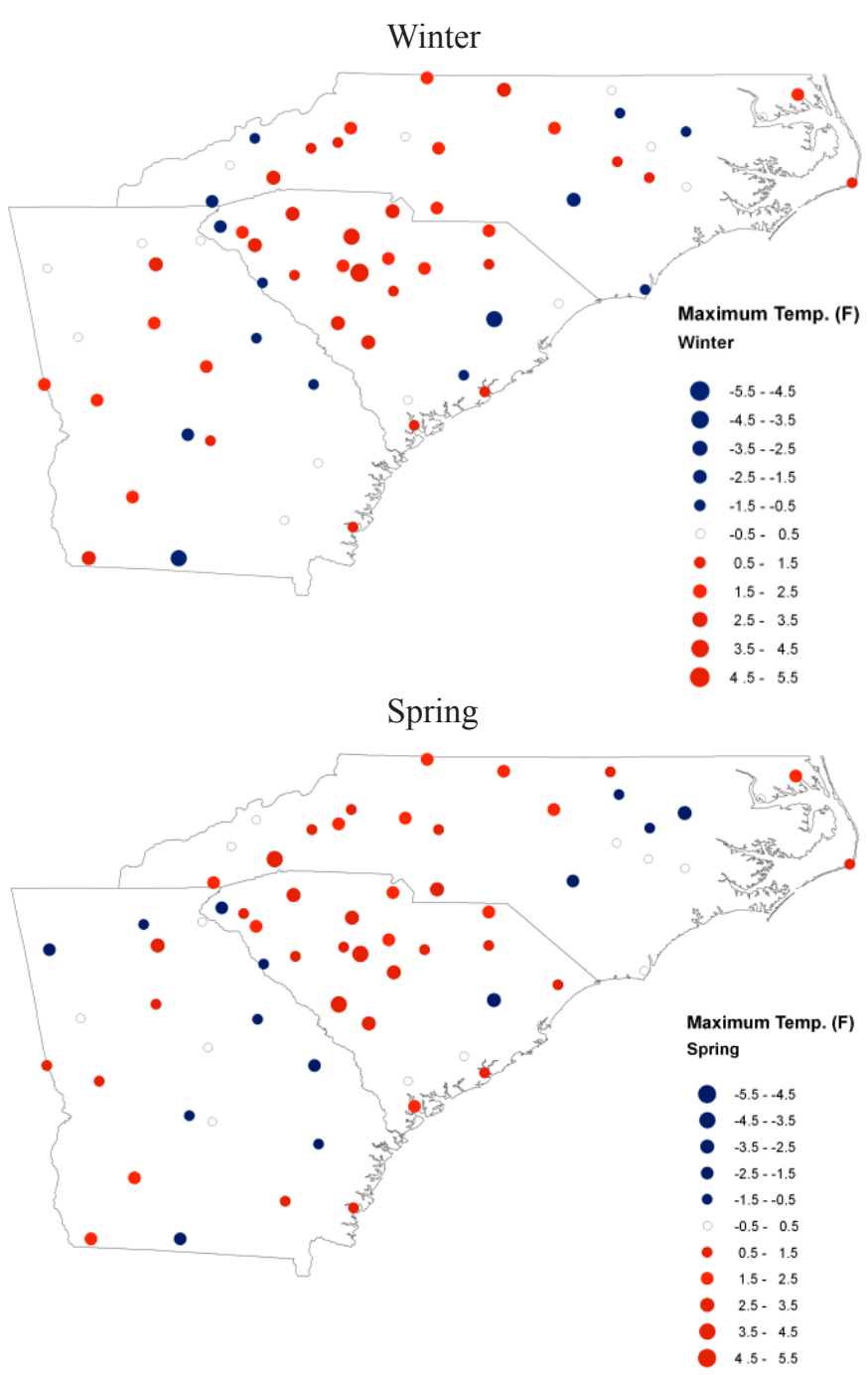

Figure 2. Trends in winter and spring maximum temperature $\left({ }^{\circ} \mathrm{F}\right)$, 1901-2010. 

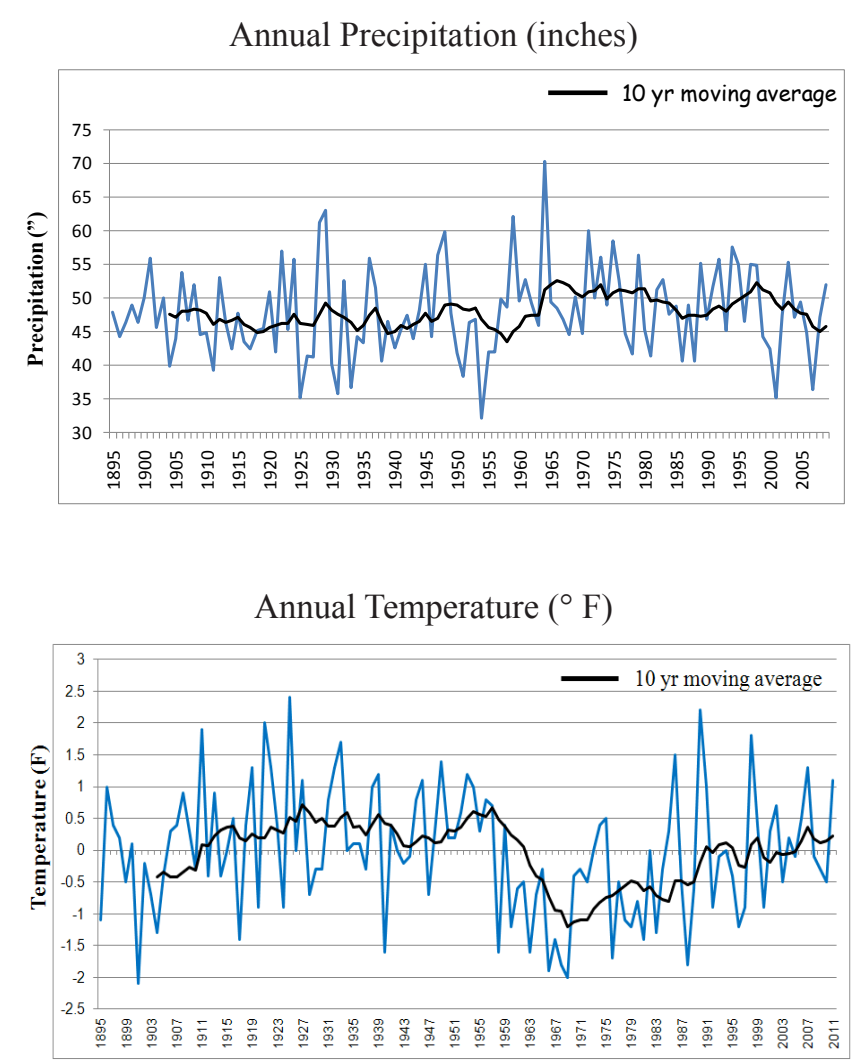

Figure 3. South Carolina annual statewide precipitation (inches) and temperature $\left({ }^{\circ} \mathrm{F}\right), 1895-2010$.

There are statistical limitations to using a linear trend to analyze climate variability, so moving averages and various threshold approaches were analyzed. The 10-year moving average for statewide annual precipitation shows a decreasing precipitation trend during the 1950s, increasing trend during the 1960s with a decreasing trend over the past decade (Figure 3). The 10-year moving average for statewide temperature shows a decreasing temperature trend from the late 1950 s through the 1960 s with a steady temperature increase since the 1970s (Figure 3). Future analysis should evaluate potential forcing mechanisms such as the El Nino Southern Oscillation that may contribute to these local variations over time.

Linear trends and 10-year moving average results from the threshold exceedance analysis will be discussed for three South Carolina stations. Walhalla, Saluda, and Charleston were selected from the State's three geographic regions (Upstate, Midlands, Coast) based on length of record (1938-2010) and data quality. The analysis for the annual number of days with temperature $\geq 95^{\circ} \mathrm{F}$ (Figure 4) reveals a decreasing linear trend for Walhalla (-0.11 days) and Saluda (-0.05 days) and an increasing linear trend for Charleston (+0.05 days). The 10-year moving average pattern

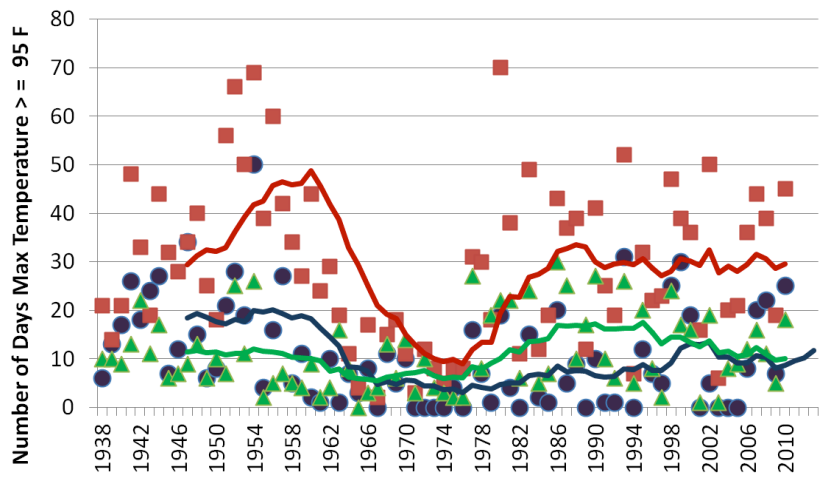

$$
\begin{array}{ll}
\text { - Walhalla } & \text { Saluda } \\
-10 \text { per. Mov. Avg. } & \quad-10 \text { per. Mov. Avg. } \quad-10 \text { per. Mov. Avg. }
\end{array}
$$

Figure 4. Annual number of days with temperature $\geq 95^{\circ} \mathrm{F}$ for Walhalla, Saluda, and Charleston, 1938-2010.

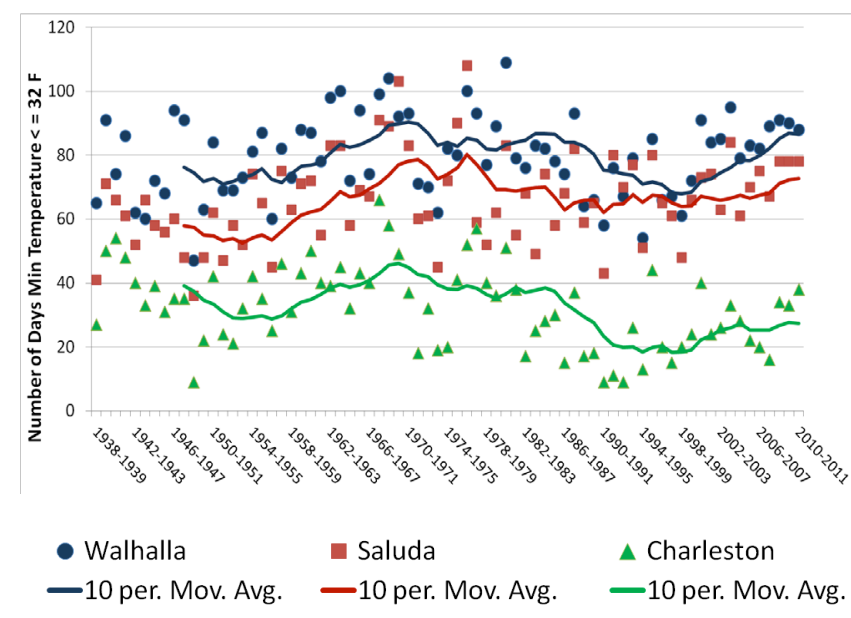

Figure 5. Fall-spring number of days with temperature $\leq 32^{\circ} \mathrm{F}$ for Walhalla, Saluda, and Charleston, 1938-2010.

for all three stations is consistent with the general temperature signal displayed in Figure 4 with warmer temperatures in the 1950 s followed by much cooler temperatures in the 1960s / 1970s and a warming trend from 1980s to present. All three stations had a greater number of days with maximum temperature above $95^{\circ} \mathrm{F}$ during the $1950 \mathrm{~s}$ and again from the 1980 s to present with a reduced number during the relatively cooler 1960s and 1970s.

Figure 5 displays the September-May number of days with minimum temperature $\leq 32^{\circ} \mathrm{F}$ for $1938-2010$. There is an increasing linear trend for Walhalla $(+0.07)$ and Saluda $(+.18)$ and a decreasing linear trend for Charleston (-0.22). The 10-year moving averages for all three stations show a general trend of increasing number of days below $32^{\circ} \mathrm{F}$ from the 1950 s into the 1960 s / 1970 s, followed by a decreasing trend through the late 1990s and then an increasing trend through 2010. 


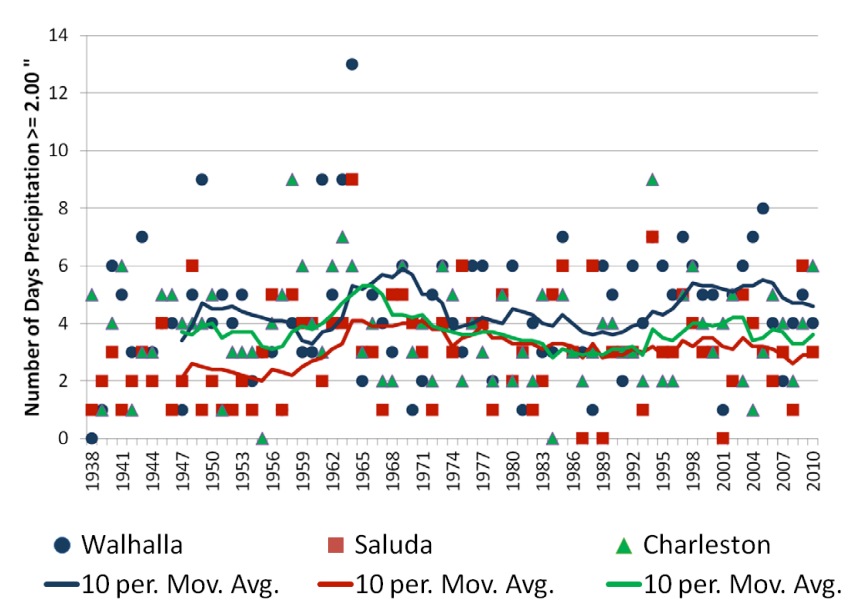

Figure 6. Annual number of days with precipitation $\geq 2.00$ " for Walhalla, Saluda, and Charleston, 1938-2010.

The evaluation of the days with heavier rainfall totals (precipitation $\geq 2.00$ ") is displayed in Figure 6 . The 10-year moving average for all three stations indicate a higher occurrence of the 2 " or greater events during the 1960s which was generally a wetter than normal decade. Even though there is variation from year to year, there is only small fluctuation in the 10year moving average for Saluda and Charleston from 1970 to present.

The next phase of the project examined the variability of severe weather focusing on tornado occurrence and hurricane landfalls in South Carolina. Tornado data from the period 1950-2010 (Figure 7) demonstrate an increasing trend in these severe storms. This increasing trend is believed to be attributable to increased population levels and the advent of Doppler radar technology in the early 1990s. Figure 7 displays the misleading appearance of an increasing trend in total tornado frequency likely due to observational biases. However, a closer examination of the EF2 and stronger tornado events in South Carolina does not show an increasing trend. The purpose of examining just the stronger tornadoes is based on the premise that these tornadoes would have more likely been reported even during the decades before Doppler radar and hence represents a more reliable way of tracking temporal trends.

There is extensive data on hurricane landfalls dating back to 1878 (Figure 8). Throughout this period South Carolina has experienced two hurricane landfalls in one season only three times (1893, 1959 and 2004). The 10year moving average suggests an active period during the late 1800 s into the early 1900 s and also during the 1950s. The longest periods without a landfalling hurricane in SC were 1960-1978 (19 years) and 19902003 (14 years).

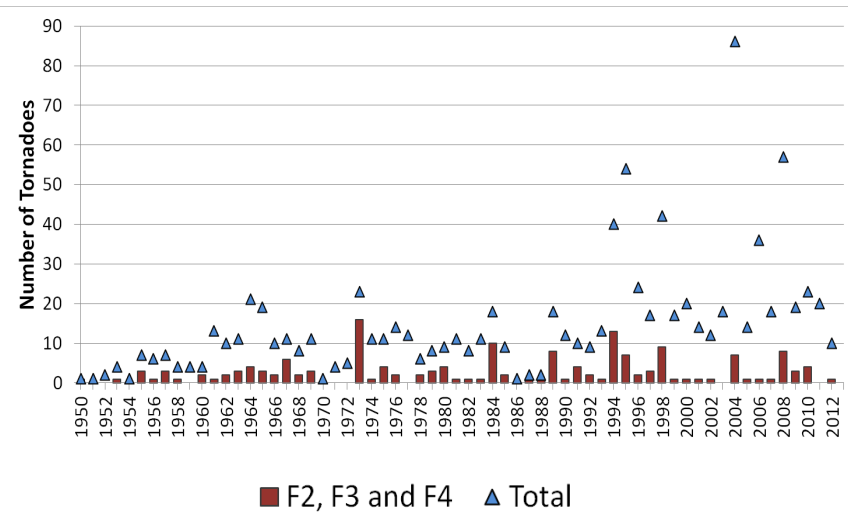

Figure 7. South Carolina annual tornado events (showing stronger events in bars).

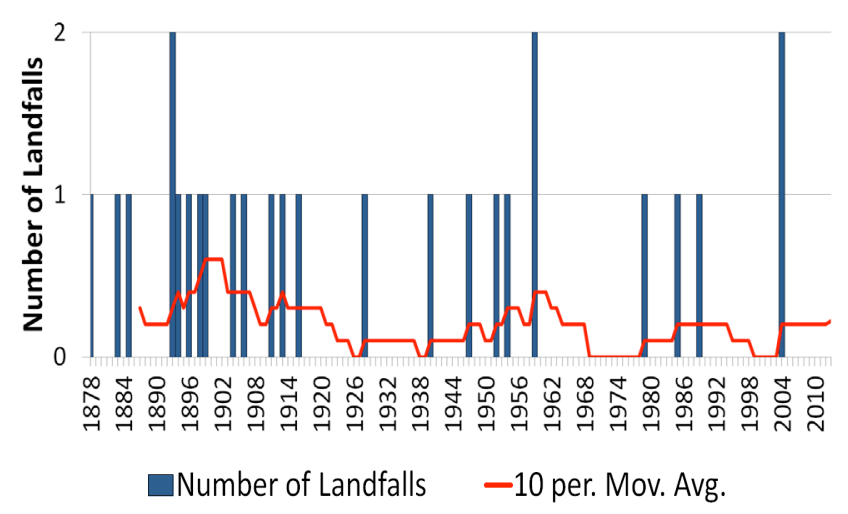

Figure 8. South Carolina hurricane landfalls, 1878-2012.

\section{CONCLUSIONS}

The average or mean state of climate, how climate varies over time, and the frequency and persistence of extreme values all influence our lives and well-being. As demonstrated in this study there is a wide range of variability in the climate system. There were years with no hurricanes, but there were years South Carolina experienced two hurricanes in one season. The annual tornado occurrence ranges from one to over eighty. There were years where some stations never reached $95^{\circ} \mathrm{F}$ while other years the mercury climbed to $95^{\circ} \mathrm{F}$ or greater on 70 days. The annual data and the 10-year moving averages display large fluctuations for many of the variables over time.

The linear trend analysis for some variables does not show a dominant and consistent change. The only consistent change among all stations was an increasing fall precipitation trend. South Carolina precipitation patterns, however, were more clearly defined than temperature with differential changes between minimum temperature (Tmin) and maximum temperature $(T \max )$ for some seasons. 
While there does not seem to be an increasing trend in the frequency of tornado occurrences and hurricane landfalls in South Carolina there is also no evidence that the events are becoming less frequent or less severe. This report will be updated every 5-years to provide information on the State's climate signal. Future work should expand the analysis to include different climate response variables such as droughts and also include additional statistical evaluations of variance and trends.

\section{LITERATURE CITED}

Holland, G.J., and P.J. Webster, 2007. Heightened tropical cyclone activity in the North Atlantic: Natural variability or climate trend? Philosophical Transactions of the Royal Society-Mathematical, Physics, and Engineering Sciences, 365 (186): 2695-2716.

Ingram, K., K. Dow, L. Carter, J. Anderson, eds. 2013. Climate of the Southeast United States: Variability, change, impacts, and vulnerability. Washington DC, Island Press.

Intergovernmental Panel on Climate Change, 2007. Climate Change 2007: The Physical Science Basis, Contribution of Working Group I to the Fourth Assessment Report of the Intergovernmental Panel on Climate Change. Solomon, S, D. Manning, Z. Chen, M. Marquis, K.B. Averyt, M. Tignor and H.L. Miller. Cambridge University Press, New York and United Kingdom.

Kunkel, Kenneth E., T. Karl, H. Brooks, J. Kossin, L. Bosart, and Coauthors, 2013. Monitoring and understanding trends in extreme storms: State of knowledge. Bulletin of the American Meteorological Society, 94: 499-514.

Landsea, C.W, 2007. Counting Atlantic tropical cyclones back to 1900. EOS, Transactions, American Geophysical Union, 88 (18): 197-208.

Landsea, C.W, 2010. Impact of duration thresholds on Atlantic tropical cyclone counts. Journal of Climate, 23: 2508-2518.

National Climatic Data Center (NCDC), 2011. Billon dollar USA Weather/Climate Disasters, http:///www. ncdc.noaa.gov/oa/reports/billionz.html.

NOAA Technical Report, NESDIS 142, 2013.

Regional Climate Trends and Scenarios for the U.S., U.S. Department of Commerce, Washington, D.C. 